\title{
On shaping expectations of "new normals" for living in a post-COVID-19 world
}

\author{
William Leeming ${ }^{1}$ (D)
}

Received: 28 November 2020 / Accepted: 21 April 2021 / Published online: 30 April 2021 (C) Springer Nature Switzerland AG 2021

\begin{abstract}
I begin with my impressions of a narrative of redemption that is caught up in the formation of new environmental, social, and political aspirations for the aftermath of the COVID-19 pandemic. I then reflect on, first, pre-pandemic scholarship on "biosecurity" and, second, taking up a variation of the syndemic approach to understanding the COVID-19 pandemic. I end by arguing that we should not expect to live with "new normals" for living in a post-COVID-19 world that leaves intact "old normals" that have historically contributed to the rise of anthropogenic environmental harms and inegalitarian social arrangements in the world today.
\end{abstract}

Keywords COVID-19 pandemic $\cdot$ Biosecurity $\cdot$ Syndemics

The global response to the COVID-19 pandemic appears to me to be generating a narrative of redemption that is caught up in the formation of new environmental, social, and political aspirations for the aftermath of the pandemic. The narrative suggests that in a post-COVID-19 world we will be better equipped to face a series of longstanding challenges which include tackling anthropogenic environmental harms in the natural world (e.g., climate change including both global warming driven by releases of greenhouse gases and resulting in large-scale shifts in weather patterns) and a range of inegalitarian social arrangements that exist in the world today (e.g.,

This paper belongs to the Topical Collection "Seeing Clearly Through COVID-19: Current and future questions for the history and philosophy of the life sciences," edited by G. Boniolo and L. Onaga

William Leeming

bleeming@faculty.ocadu.ca

1 Faculty of Liberal Arts and Science, OCAD University, 100 McCaul St, Toronto,

ON M5T 1W1, Canada 
systemic racism, enduring privation and poverty, forced migration of refugees and of stateless persons). On the face of it, the narrative seems to implicate us all (i.e., 7.7 billion living humans). But it does not say what we will be better equipped with. Instead, we are told that we can expect to live with an assortment of "new normals" in the future. Moreover, the narrative warns of the possibility that forgotten perils and forewarnings connected with the rise of natural and human-centred disasters that hounded pre-pandemic life will persist and we should not be complacent and preoccupied with the idea of returning to pre-pandemic normalcy.

The idea of a narrative of redemption first occurred to me almost four months ago when people began waiting for the release and distribution of a safe and effective vaccine against severe acute respiratory syndrome coronavirus 2 (SARS-CoV-2). There were hopeful announcements of interim results in large-scale trials for vaccine candidates of Pfizer/BioNTech, Moderna, and Oxford/AstraZeneca. Lots of questions remained unanswered including how long those vaccinated would be protected and how effective each vaccine would be for those most vulnerable to infection. Still, many countries of the Global North already had orders for these vaccine candidates and others. As time moved on, I watched with growing consternation as the daily reporting of infection rates climbed and the possibility of economic decline more and more figured prominently into the development of new forms of political governance and calls to implement surveillance measures to maintain national security. With the upsurge in hope and optimism surrounding vaccination, a race to vaccinate national citizenry before new coronavirus variants take hold has ensued. Hope and optimism in turn has been tied to "vaccine nationalism" wherein countries with domestic facilities to manufacture vaccine give preference to the needs of their national citizenry while those without facilities push to gain access. On the other hand, there has been a measure of vaccine diplomacy in the Global South with access to two vaccines not widely available in the Global North: Sputnik V (Russia) and CoronaVac (China).

Multilateral organisations such as the World Health Organization (WHO) have warned that the COVID-19 pandemic might not be the "big one" that epidemiologists have long feared. ${ }^{1}$ Since the first reports of the coronavirus began circulating, the WHO has repeatedly called for increased surveillance and the need to prepare for even deadlier pandemics in the future. Even before the pandemic, directions for different kinds of international relations in complex networks, filiations and connections were featured in scholarship on "biosecurity" from the fields of geography, anthropology, and political science (Mutsaers, 2015; Samimian-Darash et al. 2016). Building on Michel Foucault's theory of biopolitics, which had emphasised problems of circulation and unmediated flows of natural phenomena in national citizenries, the biosecurity scholarship emphasised the interwoven aspects of contagion and infectivity. A dominant theme in the scholarship promoted humans and pathogens co-existing in a continuum of adapting to each other (e.g., Barker, 2008; Biermann

\footnotetext{
1 Miriam Berger, "Covid-19 'not necessarily the big one,' WHO warns," The Washington Post (Dec. 29, 2020). URL: https://www.washingtonpost.com/world/2020/12/29/coronavirus-2020-the-big-one-whopandemics/. Accessed 2021-01-2.
} 
\& Mansfield, 2014; Hinchliffe \& Lavau, 2013). By way of an example, geographer Steve Hinchliffe and historian Nick Bingham's proposal (2008) for organising enclosed disease-free areas (i.e., "territorial units") recommended that there would be "less the need to shore up borderlines between the healthy and the diseased and more the requirement to engage with infected life as part of a borderlands within a mutable disease environment" (Hinchliffe et al. 2013, p. 532, emphasis in the original). Decisively, the term "mutable" suggested the ability to adapt and change into something new. Geographer Bruce Braun here argued; "what we find in the medical and political discourse of 'emerging infectious diseases' is a body that is radically open to the world, thrown into the flux of an inherently mutable molecular life where reassortment is not what we control, but what we fear" (2007, p. 17). Indeed, seemingly interminable lockdowns and other restrictions remain in effect with countries entering third waves of infections. The mutability of the coronavirus and its variants is portrayed here as competing with governments for what political scientist Benjamin Muller (2004) called the "securitization of the inside."

It may be tempting to think that the securitization of the inside during the COVID-19 pandemic resembles pre-pandemic "immunological discourse" in political philosophy (Küpers, 2020, cf. Mutsaers, 2016). But, importantly, as W. J. T. Mitchell has pointed out: "The whole theory of the immune system and the discipline of immunology is riddled with images drawn from the sociopolitical sphereof invaders and defenders, hosts and parasites, natives and aliens, and of borders and identities that must be maintained. The effect ... is to produce a situation in which there is no literal meaning, nothing but the resonances between two images, one biomedical, the other political" (2007, p. 282, emphasis in the original). What remains salient, following essayist Susan Sontag's earlier pronouncements on militaristic metaphors in the rhetoric of AIDS discourse, is the need to assess critically any political agendas that intend to acclimatise us with "the intermittent awareness of a monstrous, unthinkable — but we are told quite probable-pandemic catastrophe" (Sontag Sontag, 1989, p.88). What political economist Melinda Cooper (2006) labelled "speculative pre-emption," for instance, involves "a profoundly new strategic agenda where war is no longer waged in the defence of the state ... or even human life ... but in the name of life in its biospheric dimension, incorporating meteorology, epidemiology and the evolution of all forms of life, from the microbe upwards" (Cooper, 2006, p. 129; emphasis in the original). This stems from the idea that "some global hazards might, in their very nature, be [a threat to humans and] they cannot be prevented unless pre-emptive action is taken immediately ... Unless we act now on uncertain claims, catastrophic and irreversible results might unfold beyond human control" (Haller, 2002, p. 14; cited in Cooper, 2006, p. 120; Cooper's emphasis).

In contrast, sociologist Steven Yearley's recent survey of the political, ethical, and societal aspects of issuing scientific warnings is instructive for what it has to say about the problems inherent in "attempts to "speak truth to humanity'-despite the undoubted quality of the analyses and the accuracy of underlying data" (2020, p. 23). Focusing on environmental warnings and declarations of a climate emergency, Yearley starts by pointing to the widely held assumption "that 'humanity' has a unified outlook on global environmental problems" (2020, 
p. 19). "Quite the reverse," he notes, "there are significant areas of people's lives where they are very limited in their ability to choose" $(2020$, p. 20$)$. Whether it be deep-rooted optimism or pessimism in neoliberal programs of resilience to design solutions to environmental problems or the fear that customary rights or freedoms of citizens are eroding, there are "messy and complex reasons [shaping expectations of the future], leading to inconsistent responses to emergency conditions" (2020, p. 24). Importantly, Yearley's study calls attention to a line of argumentation that "even the more technical aspects of the warning documents may contain normative or social scientific components; despite their appearances, the warnings are not exclusively technical."

All things considered, geographer Kezia Barker is likely right in predicting the self-referentiality of biosecurity and biosecure citizenry will remain embedded in affairs of state in ways that ensure "the nation state [maintains] the symbolic space of biosecure citizenship" (Barker, 2010, p. 356). But I cannot imagine that new environmental, social, and political aspirations for the aftermath of the COVID-19 pandemic can support new normals that bring to light a sudden and unprecedented scalar shift in social imaginaries to capture notions of humans and non-humans (i.e., pathogens) co-existing in a continuum of adapting to each other. Be that as it may, I can envision directions for writing a narrative of redemption that attends to making amends for living, when possible, in a precipitously changing world of natural and humanitarian challenges. Just to be clear, I am less interested in formulating a unified outlook on the state of humanity after the pandemic than in making amends for longstanding anthropogenic environmental harms in the natural world and inegalitarian social arrangements. I have no illusions about the COVID-19 pandemic, in and of itself, will be a turning point where redemption for human harms and injustices of the past begins to realize itself. The possibility of forgetting perils and forewarnings connected with the rise of natural and human-centred disasters that hounded pre-pandemic life is nonetheless all too real. Accordingly, as an alternative to fixating on biosecurity, I support taking up a variation of the syndemic approach to understanding COVID-19 in ways that do not gloss over longstanding challenges for the future surrounding anthropogenic environmental harms and inegalitarian social arrangements (cf. Horton, 2020).

Syndemic or synergistic epidemics have been studied by epidemiologists and medical anthropologists concerned with public health, community health and the effects of social conditions on health. On a high level of generality, syndemics is a biosocial conception of health which includes the practical need to monitor "the social and environmental factors that promote and enhance the negative effects of disease interaction" (Singer et al. 2017, p. 941). The social and environmental factors that syndemics monitor "involve the adverse interaction between diseases and health conditions of all types (eg, infections, chronic non-communicable diseases, mental health problems, behavioural conditions, toxic exposure, and malnutrition) and are most likely to emerge under conditions of health inequality caused by poverty, stigmatisation, stress, or structural violence" (Ibid).

Early on in the pandemic, Richard Horton, editor-in-chief of The Lancet, made a case for arguing: "COVID-19 is not a pandemic. It is a syndemic." 
We have viewed the cause of this crisis as an infectious disease. All of our interventions have focused on cutting lines of viral transmission, thereby controlling the spread of the pathogen. The "science" that has guided governments has been driven mostly by epidemic modellers and infectious disease specialists, who understandably frame the present health emergency in centuries-old terms of plague. (2020)

In arguing the case for a COVID-19 syndemic, he identified circumstances that were not simply about comorbidity of contributing factors to disease but "an array of non-communicable diseases ... conditions are clustering within social groups according to patterns of inequality deeply embedded in our societies."

Responding to Horton, Emily Mendenhall, one of the medical anthropologists who had been involved in defining syndemics in 2017, added that "[c]alling COVID-19 a global syndemic is misguided."

... I believe COVID-19 is syndemic in my country (the USA). This is precisely because pre-existing conditions such as hypertension, diabetes, respiratory disorders, systemic racism, mistrust in science and leadership, and a fragmented health-care system have driven the spread and interacted with the virus. These synergistic failures have caused more death and devastation than many other contexts. (Mendenhall, 2020)

There was a shift in context when it came to "doing much better" in other countries, she argued, like sub-Saharan Africa and New Zealand. National context, then mattered with respect to "where global knowledge and power sit within fields like global health."

Four months on, with responses to COVID-19 focusing globally on the relative success of mask-wearing, physical distancing, regional lockdowns and vaccination campaigns, it is prudent to now reconsider how the surveillance and control of the pathways of contagion have been complicated by a plethora of small- and large-scale tipping points being reached in the different national experiences of COVID-19 around the world. With hindsight, we have seen reversals in many of the countries that were "doing much better." Renewed emphasis on infectivity has seen a shift in vaccination campaigns from prioritising the most vulnerable based on age to those who are at higher risk for infection (e.g., living in multigenerational households, having more public-facing jobs). At the same time, vaccine distribution has expanded from hub-and-spoke models to include "pop up" access points in "hot spots" (i.e., areas with higher rates of death, hospitalisation and transmission). Even so, "COVID fatigue" has been accompanied by a range a complex of emotions that include loneliness, anxiety, fear, anger, and resentment, all brought on by the loss of activities and social relations produced by pandemic restrictions. On a sociopolitical level this has resulted in growing civil unrest including anti-closure protests egged on by politicians incessantly calling to re-start economies during the pandemic. Attempts to close pathways of pathogenic traffic have been increasingly made porous by attempts to keep supply chains open. But that being said, in contrast to the borderless world of globalisation, the calculation of what are and what are not essential goods and services replaces the free flow of capital, goods, and 
people around the world. This all occurs against a backdrop of the wide diversity of how communities experience COVID-19 differently around the world. But therein lies the rub: Should old pre-pandemic normals be left intact that have historically contributed to the rise of anthropogenic environmental harms in the natural world as well as the inegalitarian social arrangements that exist in the world today? I think not.

\section{References:}

Barker, K. (2008). Flexible boundaries in biosecurity: Accommodating gorse in Aotearoa New Zealand. Environment and Planning A, 40(7), 1598-1614

Barker, K. (2010). Biosecure citizenship: Politicising symbiotic associations and the construction of biological threat. Transactions of the Institute of British geographers, 35(3), 350-363

Biermann, C., \& Mansfield, B. (2014). Biodiversity, purity, and death: Conservation biology as biopolitics. Environment and Planning D: Society and Space, 32(2), 257-273

Braun, B. (2007). Biopolitics and the molecularization of life. Cultural Geographies, 14(1), 6-28

Cooper, M. (2006). Pre-empting emergence: The biological turn in the war on terror. Theory, Culture and Society, 23(4), 113-135

Haller, S. F. (2002). Apocalypse soon? Wagerings on warnings of global catastrophe. Montreal: McGillQueen's University Press.

Hinchliffe, S., \& Bingham, N. (2008). Securing life: The emerging practices of biosecurity. Environment and Planning A, 40(7), 1534-1551

Hinchliffe, S., Allen, J., Lavau, S., Bingham, N., \& Carter, N. (2013). Biosecurity and the topologies of infected life: From borderlines to borderlands. Transactions of the Institute of British Geographers, 38(4), 531-543

Hinchliffe, S., \& Lavau, S. (2013). Differentiated circuits: The ecologies of knowing and securing life. Environment and Planning D: Society and Space, 31(2), 259-274

Horton, R. (2020). Offline: COVID-19 is not a pandemic. The Lancet, 396(10255), 874

Küpers, W. (2020). From the anthropocene to an 'ecocene'-eco-phenomenological perspectives on embodied, anthrodecentric transformations towards enlivening practices of organising sustainably. Sustainability, 12(9), 3633-3653

Mendenhall, E. (2020). The COVID-19 syndemic is not global: Context matters. The Lancet, 396(10264), 1731

Mitchell, W. T. J. (2007). Picturing terror: Derrida's autoimmunity. Critical Inquiry, 33(2), 277-290

Muller, B. J. (2004). (Dis)qualified bodies: Securitization, citizenship and "identity management." Citizenship Studies, 8(3), 279-294

Mutsaers, I. (2015). One-health approach as counter-measure against "autoimmune" responses in biosecurity. Social Science and Medicine, 129, 123-130

Mutsaers, I. (2016). Immunological discourse in political philosophy: Immunisation and its discontents. London: Routledge.

Samimian-Darash, L., Henner-Shapira, H., \& Daviko, T. (2016). Biosecurity as a boundary object: Science, society, and the state. Security Dialogue, 47(4), 329-347

Singer, M., Bulled, N., Ostrach, B., \& Mendenhall, E. (2017). Syndemics and the biosocial conception of health. The Lancet, 389(10072), 941-950

Sontag, S. (1989). AIDS and its metaphors. Farrar, Straus and Giroux.

Yearley, S. (2020). Political, ethical, and societal aspects of issuing warnings to humanity. Ecocene: Cappadocia Journal of Environmental Humanities, 1(1), 19-25

Publisher's Note Springer Nature remains neutral with regard to jurisdictional claims in published maps and institutional affiliations. 